\title{
MALDI-TOF-MS Analysis of Small Molecules Using Modified Mesoporous Material SBA-15 as Assisted Matrix
}

\author{
Xiuhua Li, ${ }^{\text {a,b }}$ Xue $\mathrm{Wu}^{\text {a }}$ Ji Man Kim, ${ }^{\mathrm{c}}$ Sung Soo Kim, ${ }^{\mathrm{c}}$ Mingshi Jin, ${ }^{\mathrm{c}}$ and \\ Donghao Li $\mathrm{i}^{\mathrm{a}, \mathrm{b}}$ \\ ${ }^{a}$ Key Laboratory of Nature Resource of Changbai Mountain and Functional Molecular (Yanbian University), \\ Ministry of Education, Jilin, China \\ ${ }^{\mathrm{b}}$ Chemistry Department, Yanbian University, Jilin, China \\ ${ }^{c}$ Department of Chemistry, BK21 School of Chemical Materials Science, Department of Energy Science and \\ SKKU Advanced Institute of Nanotechnology, Sungkyunkwan University, Suwon, Korea
}

\begin{abstract}
Mesoporous silica, SBA-15 was successfully functionalized with quinoline moiety, and was applied as a matrix in the MALDI-TOF-MS analysis of small molecules. The modified SBA-15 material [SBA-15-8-(3-(triethoxysilyl)propoxy) quinoline, SBA-15-8QSi] was obtained by using calcined SBA-15 and 8-hydroxy quinoline. The structure of the functionalized mesoporous material was systemically characterized by TEM, the $\mathrm{N}_{2}$ adsorption-desorption isotherm technique and FT-IR spectra. Compared with DHB and SBA-15, SBA-15-8QSi demonstrated several advantages in the analysis of small molecules with MALDI-TOF-MS, such as less background interference ions, high homogeneity, and better reproducibility. Based on these results, the various analytical parameters were optimized. The ideal operating conditions were (1) methanol used as the dissolving solvent; (2) sample first dropping method; (3) a ratio between the analyte and the matrix of 3.5:10. Under these optimization conditions, a low detection limit (8 pmol for L-Arginine-HCl) and high reproducibility $(\leq 29 \%)$ were obtained. This technique was successfully applied to the analysis of various types of small molecules, such as saccharides, amino acids, metabolites, and natural honey. (J Am Soc Mass Spectrom 2009, 20, 2167-2173) (c) 2009 American Society for Mass Spectrometry
\end{abstract}

$\mathrm{S}$ ince the development of MALDI-TOF-MS by Karas and Hillenkamp [1] and Tanaka [2] et al., this technique has been successfully utilized in the analysis of various types of biochemical materials, including peptides/proteins [3-5], oligosaccharides [6], oligonucleotides [7], and synthetic polymers [8, 9]. However, the application of MALDI-TOF-MS in small molecules analysis has been limited, mainly due to ion interference originating from matrices in the low molecule weight region $(<500 \mathrm{Da})[10,11]$. To overcome this problem, several alternative matrices, such as high mass molecules [12, 13], surfactant suppressed matrix [14], inorganic materials [15], and $C_{60}$ [16] have been investigated. Recent developments, which are often referred to as nanoscience, have enabled significant advances in the understanding of matrix materials at the molecular level and have revealed the importance of the nanometer-scale properties of matrices, such as pore size, surface functional groups, and compositions in their consequent matrix performances. For example, nanostructured materials, such as porous silicon [17], silicate [18, 19], silicon nano-particles [20], carbon nanotubes [21], and gold nano-particles [22] have been

Address reprint requests to Dr. D. Li, Chemistry Department, Yanbian University, Park Road 977, Yanji City, Jilin Province, China. E-mail: dhli@ybu.edu.cn utilized as matrix materials, exhibiting no or little matrix ion background in the mass spectra.

There has been a great deal of interest in ordered mesoporous materials due to their regular pore sizes in the mesoporous range, high surface areas, high pore volumes, and easy functionalization since they were first reported in 1992 [23, 24]. Recently, there have been significant advances in the preparation and modification of mesoporous materials, which allows their utilization in various applications, such as adsorbents [25], catalyst supports [26], nano-templates [27], and nanomaterials [28] for advanced electronics. In general, the pore surfaces of mesoporous silica materials are covered with a layer of silanol groups $(\mathrm{Si}-\mathrm{OH})$, which can act as the binding sites for desired functional groups via covalent grafting on the surfaces. Hu et al. reported on titanium (IV) immobilized mesoporous silica particles which were used as an enriching trap for small molecules (phosphorylated peptides), determined with MALDITOF-MS [29]. In addition, mesoporous silica materials have the advantage of optical transparency in the visible region [30].

Herein, we successfully functionalized the mesoporous silica, SBA-15 with an 8-hydroxy quinoline group (SBA-15-8QSi hereafter), and applied the functional material as a matrix for MALDI-TOF-MS analysis. The SBA-15-8QSi material exhibited less ion back- 
ground and more signal intensity, compared with the 2,5-dihydroxybenzoic acid (DHB) matrix, which is generally used as a standard matrix in MALDI analysis. The detection limits and reproducibility of this modified mesoporous matrix were investigated to understand the behavior of MALDI-TOF-MS. The technique was also used to analyze various types of small molecular weight chemical mixtures such as amino acids (4), metabolites (2), saccharides (3) and honeys.

\section{Experimental}

\section{Chemicals and Materials}

Organic solvents such as methanol, acetone, acetonitrile $(\mathrm{ACN})$, toluene, and 2-propanol (HPLC grade), trifluoroacetic acid (TFA), $\alpha$-cyano-4-hydroxycinnamic acid (CHCA), bradykinin standards, 2,5-dihydroxybenzoic acid (DHB, a standard MALDI matrix), pluronic P123 $\left(\mathrm{EO}_{20} \mathrm{PO}_{20} \mathrm{EO}_{20}, M_{a v}=5800\right)$, tetraethyl orthosilicate (TEOS), 8-(3-(triethoxysilyl)propoxy)quinoline (8QSi), and $\mathrm{D}(+)$-Xylose were purchased from Sigma-Aldrich. $\mathrm{D}(+)-$ glucose and sucrose were obtained from the United States Biotechnology Company (Shanghai, China). L-arginine-HCl, L-histidine, L-lysine-HCl, L-phenylalanine, L-carnosine, and cytidine were obtained from J and K Chemical Ltd (Shanghai, China). Honey was obtained from local bee farms (Yanji City, Jilin Province, China). The water used in all experiments was prepared using a Milli- $Q$ water purification system (Millipore, Milford, MA, USA). The mesoporous silica, SBA-15, was synthesized following the procedures described previously [31], using P123 as the structure-directing agent and TEOS as the framework source.

\section{Surface Modification of SBA-15 with 8QSi}

The as-prepared mesoporous silica, SBA-15 was calcined at $550{ }^{\circ} \mathrm{C}$ for $2 \mathrm{~h}$ under static air conditions, before the surface modification with $8 \mathrm{QSi} ; 1.0 \mathrm{~g}$ of the calcined SBA-15 was added to $10 \mathrm{~mL}$ of a toluene solution containing $0.32 \mathrm{~g}$ of $8 \mathrm{QSi}$, the mixture was stirred at $80^{\circ} \mathrm{C}$ for $24 \mathrm{~h}$, and the temperature was subsequently raised to $120^{\circ} \mathrm{C}$ for $24 \mathrm{~h}$. The solid material was filtered, washed sequentially with toluene, acetone, methanol, and dichloromethane, and finally dried under vacuum at room temperature. The modified SBA-15 material was denoted as SBA-15-8QSi.

\section{Sample Preparation for MALDI-TOF-MS Analysis}

Matrix solutions: $10 \mathrm{mg} \mathrm{mL}^{-1}$ of CHCA solution was obtained with a $1: 1$ volumetric ratio of $\mathrm{ACN}$ to $0.1 \%$ TFA and $10 \mathrm{mg} \mathrm{mL}^{-1}$ of DHB solution was obtained with methanol. Two different SBA-15-8QSi (10 mg $\mathrm{mL}^{-1}$ ) solutions were prepared in methanol and water.

Sample solutions: $10 \mathrm{mg} \mathrm{mL}^{-1}$ of sucrose solution was prepared with methanol to obtain a mother solution. Standard spiked honey $\left(3.5 \mathrm{mg} \mathrm{mL}^{-1}\right)$ and natural honey solutions were prepared with water; $3.5 \mathrm{mg}$ $\mathrm{mL}^{-1}$ of amino acids, metabolites, and low molecular weight saccharides were also prepared with water.

Four different sample preparation methods were used as follows. (1) Dried-Droplet method: $0.5 \mu \mathrm{L}$ of sucrose solution was mixed with $0.5 \mu \mathrm{L}$ of SBA-15-8QSi solution on a stainless steel 384-well target and allowed to air dry. (2) Matrix-first two layer method: $0.5 \mu \mathrm{L}$ of SBA-15-8QSi solution was deposited first onto the target and left to dry. Then, $0.5 \mu \mathrm{L}$ of the sucrose was deposited onto the first layer and allowed to air dry. (3) Sample-first two layer method: $0.5 \mu \mathrm{L}$ of sucrose solution was deposited first onto the plate and left to air dry. Then, $0.5 \mu \mathrm{L}$ of SBA-15-8QSi solution was deposited onto the first layer and allowed to air dry. (4) Sandwich method: $0.25 \mu \mathrm{L}$ of SBA-15-8QSi solution was deposited first onto the sample plate and left to dry. Then, $0.5 \mu \mathrm{L}$ of sucrose solution was deposited onto the first layer and allowed to air dry. Last, $0.25 \mu \mathrm{L}$ of SBA-15-8QSi solution was deposited onto the second layer and allowed to air dry.

\section{Characterization Methods}

$\mathrm{N}_{2}$ adsorption-desorption isotherms were obtained using a Micromeritics ASAP 2000 (Ontario, Canada) at liquid $\mathrm{N}_{2}$ temperature. Transmission electron microscopy (TEM) images were obtained using a JEOL JEM$2100 \mathrm{~F}$ (Tokyo, Japan), operating at $200 \mathrm{kV}$. The microscopy images were obtained using an Olympus BX61 (New York, USA). The FT-IR spectra were recorded on a Shimadzu, Tokyo, Japan Prestige-21 spectrometer with $\mathrm{KBr}$ pellets. MALDI-TOF-MS experiments were performed in positive-ion mode on a reflection-type time of flight (TOF) mass spectrometer (Kratos PC Axima CFR plus V2.4.0; Shimadzu) equipped with a $2.25 \mathrm{~m}$ flight tube. Desorption/ionization was obtained by using a 337-nm nitrogen laser and the available accelerating voltages ranged from +20 to $-20 \mathrm{kV}$. To obtain good resolution and signal-to-noise $(\mathrm{S} / \mathrm{N})$ ratios, the laser power was adjusted to slightly above the threshold and each mass spectrum was generated by averaging 300 laser pulses. The calibration of mass spectra was performed externally using the mass peaks of the dimer of CHCA and bradykinin standards.

\section{Results and Discussion}

\section{Characterization of SBA-15-8QSi Material}

The TEM images in Figure 1 confirmed that the SBA15-8QSi material had highly ordered 2D-hexagonal mesostructures and well-developed mesopores throughout the sample. It was demonstrated that the mesostructure of the SBA-15 material was preserved after functionalization with 8QSi.

$\mathrm{N}_{2}$ adsorption-desorption experiments were performed to further investigate the structural properties of the SBA-15-8QSi material. The isotherms and the 

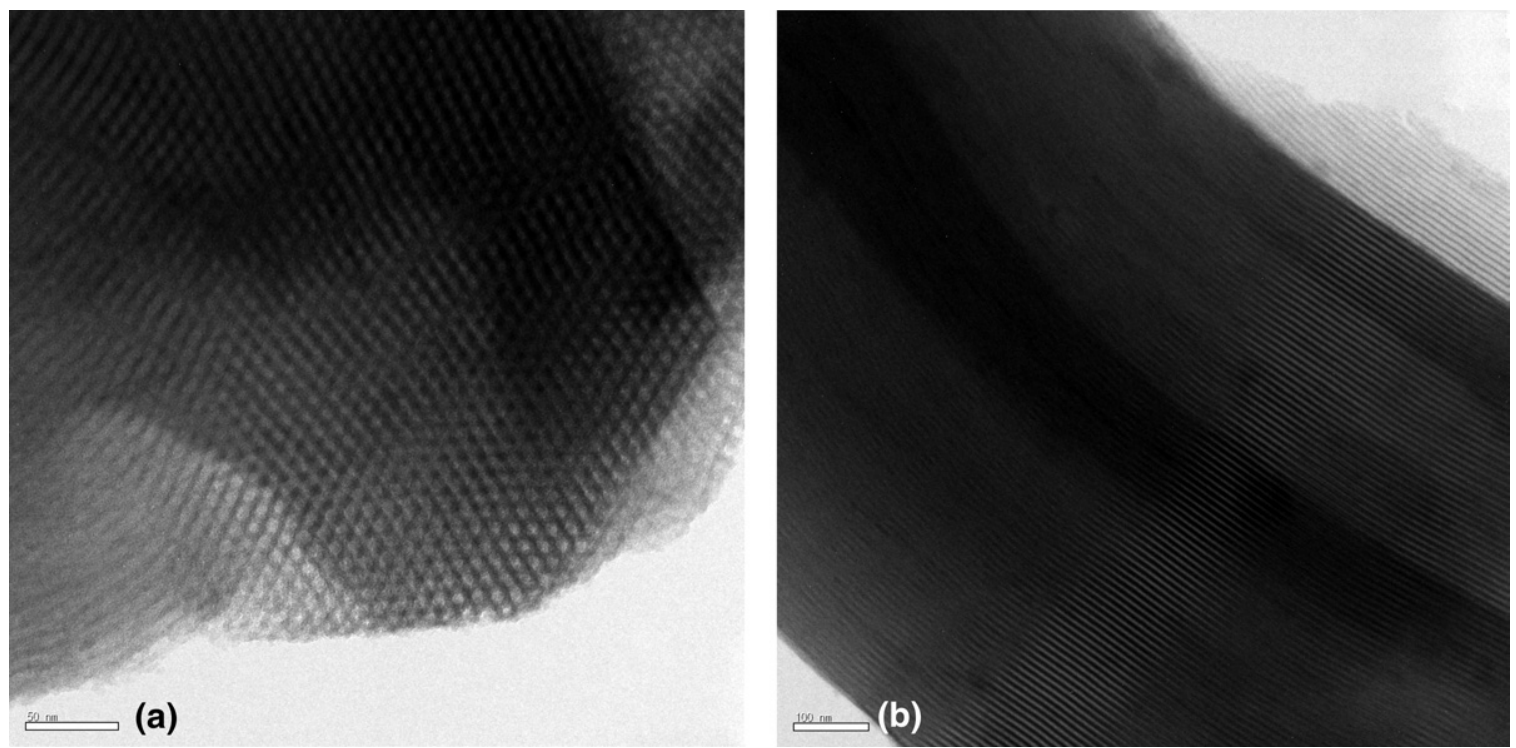

Figure 1. TEM images of SBA-15-8QSi (a) in the direction of the pore axis, and (b) in the direction perpendicular to the pore axis.

corresponding pore size distribution curves (obtained by Barrett-Joyner-Halenda (BJH) method) are shown in Figure 2. The isotherm of SBA-15-8QSi was type IV (IUPAC classification) with H1 hysteresis loops, which are typical isotherm patterns of mesoporous materials with 2D-hexagonal symmetry [32]. As expected from the sharp condensation steps in the region of $p / p_{0}=$ $0.6-0.8$ in the isotherms, the SBA-15-8QSi material exhibited a very narrow $\mathrm{BJH}$ pore size distribution curve centered at $7.2 \mathrm{~nm}$. The surface area [estimated by Branauer-Emmett-Teller (BET) method] of the SBA-15$8 \mathrm{QSi}$ material was $668 \mathrm{~m}^{2} \mathrm{~g}^{-1}$. The smaller BJH pore size and lower BET surface area of SBA-15-8QSi compared with SBA-15 $\left(\mathrm{S}_{\mathrm{BET}}=702 \mathrm{~m}^{2} \mathrm{~g}^{-1}\right.$, pore size $\left.=7.3 \mathrm{~nm}\right)$, might be due to the functional groups $(8 \mathrm{QSi})$ on the pore surface of SBA-15. Similar results were reported by $\mathrm{Li}$ et al. [30].
FT-IR spectra were obtained to investigate the chemical properties of the mesoporous materials. As shown in Figure 3, the SBA-15-8QSi material exhibited bands around $2900 \mathrm{~cm}^{-1}$ (assigned to the $\mathrm{C}-\mathrm{H}$ stretching and deformation vibrations) and around $1500 \mathrm{~cm}^{-1}$ [corresponding to the bending vibrations of imine $(C=N)$ group], whereas the IR spectrum of the SBA-15 material did not show these bands from organic moieties. These IR results also indicated the successful surface functionalization of SBA-15 with 8QSi.

\section{Comparing DHB,SBA-15, and SBA-15-8QSi as a Matrix for MALDI-TOF-MS Analysis}

To investigate the behavior of SBA-15-8QSi for MALDITOF-MS analysis, comparative studies were also car-
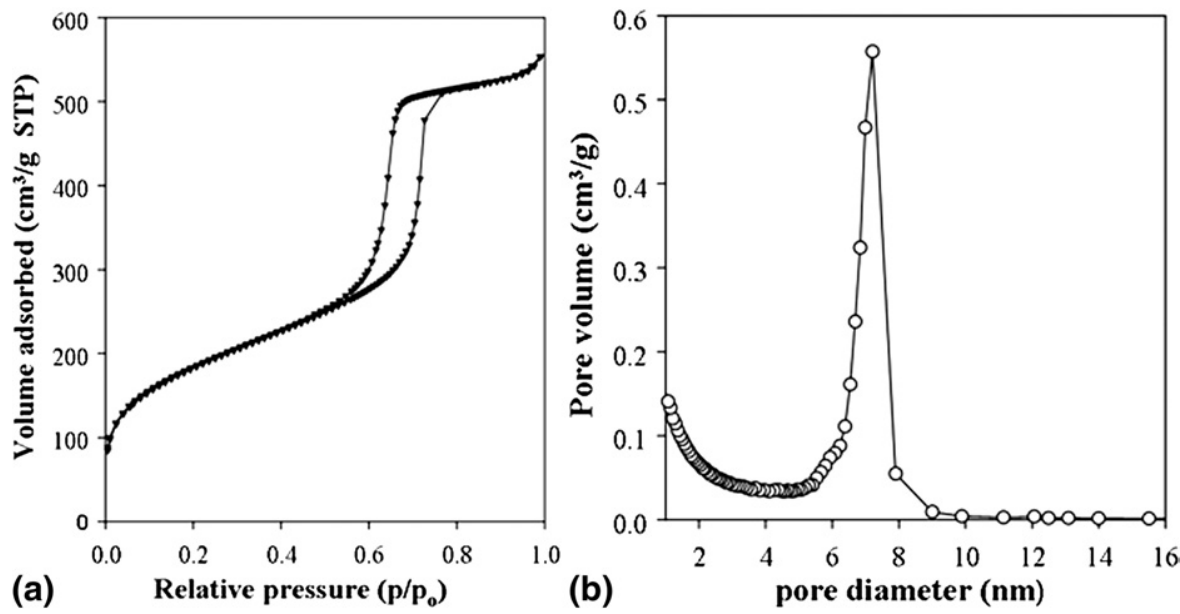

Figure 2. $\mathrm{N}_{2}$ adsorption-desorption isotherm of SBA-15-8QSi (a) and the corresponding BJH pore size distribution curve $(\mathbf{b})$. 


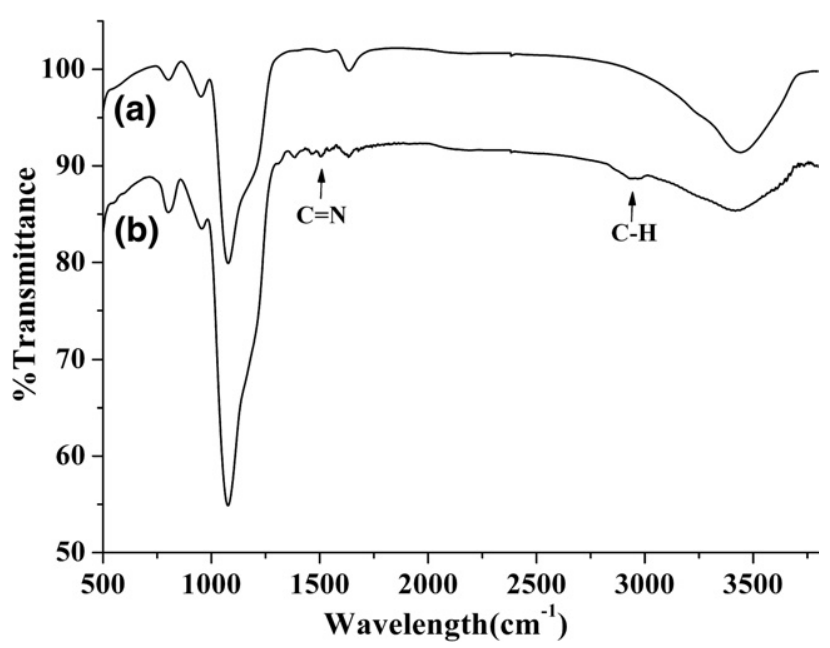

Figure 3. FT-IR spectra of (a) SBA-15 and (b) SBA-15-8QSi.

ried out using DHB and SBA-15 as the matrices. Figure 4 (inset) shows the MALDI blank matrix spectra of DHB, SBA-15, and SBA-15-8QSi. As shown in Figure 4a (inset), there were strong interference ions caused by the DHB matrix, which were due to the DHB matrix cluster ionization. In contrast, SBA-15 (Figure $4 \mathrm{~b}$, inset) and SBA-15-8QSi (Figure 4c, inset) showed spectra with little background ion interferences. The peaks above $\mathrm{m} / \mathrm{z}=100$ make the characterization of small molecules obscure and different from those in Figure 4a (inset). Although the peaks of $m / z$ at $23\left(\mathrm{Na}^{+}\right)$and $39\left(\mathrm{~K}^{+}\right)$were found sometimes, they did not affect the analysis of small molecules, and may be from the solvent or the environments. These results indicated that the mesoporous matrices (SBA-15 and SBA-15-8QSi) were good candidate materials in the MALDI-TOF-MS analysis of small molecules due to the absence of interference with matrix peaks in these ranges.

To confirm the above results, sucrose $\left(3.5 \mathrm{mg} \mathrm{mL}^{-1}\right)$ was selected as a typical small molecule, and was analyzed with MALDI-TOF-MS using DHB, SBA-15, and SBA-15-8QSi as matrices. As shown in Figure 4a, various signal peaks, such as the peaks of $\mathrm{m} / \mathrm{z}$ at 310 , 198, and 177, were observed, which may have been caused by the DHB matrix itself. In the case of SBA-15 (Figure $4 \mathrm{~b}$ ) and SBA-15-8QSi (Figure 4c), the matrix ion interferences observed in DHB were completely eliminated during the desorption/ionization of sucrose on MALDI-TOF-MS.

Furthermore, the performance (intensity, reproducibility, and distribution homogeneity) of MALDI-TOFMS was significantly improved by the SBA-15-8QSi matrix. In a comparison of the spectra obtained from SBA-15-8QSi and SBA-15, the intensity and efficiency of desorption/ionization for sucrose on SBA-15-8QSi was greatly enhanced compared with the SBA-15 matrix. This can probably be attributed to the existence of the organic functional groups on the porous surface. The 8QSi group was attached to SBA-15 as a laser power receptacle. To explain this phenomenon, the UV-Vis spectrum of SBA-15, SBA-15-8QSi, and 8QSi were compared (Figure S1, Supplementary Material, which can be found in the electronic version of this article). From the spectrum, it is found that absorbability of UV energy (between 300 and $350 \mathrm{~nm}$ ) of SBA-15-8QSi was greatly improved compared with SBA-15 after the introduction of $8 \mathrm{QSi}$ to SBA-15. This energy may have come from $8 \mathrm{QSi}$ as shown in Figure S1. It was also noted that distribution homogeneity was one of the
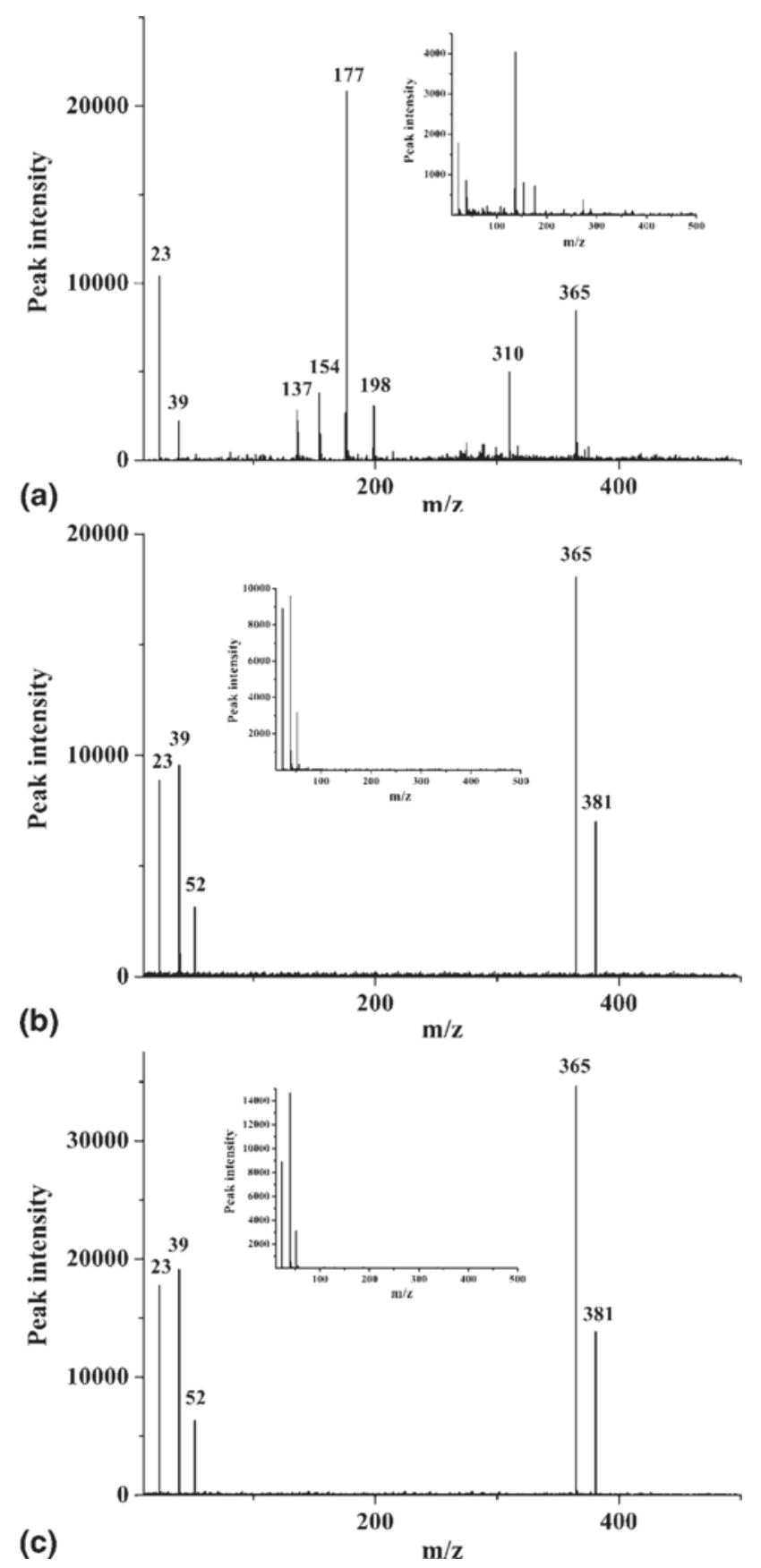

Figure 4. MALDI-TOF mass spectra of different matrices for sucrose (3.5 mg mL $\mathrm{mg}^{-1}$ ) analysis: (a) DHB, (b) SBA-15, and (c) SBA-158QSi. A comparison of the performance of the different blank matrices for MALDI-TOF-MS analysis: DHB (a, inset), SBA-15 (b, inset) and SBA-15-8QSi (c, inset). 
most important factors affecting intensity and reproducibility of mass spectra in the MALDI-TOF-MS technique. It was observed that the SBA-15-8QSi matrix made the spot distribution more homogeneous than the SBA-15 matrix on the stainless steel target. As we know, SBA-15 materials have high surface energy. The silanol groups on the surface possess high chemical and physical activities. Therefore, the introduction of $8 \mathrm{QSi}$ reduced the surface activity (such as Coulomb's force), and this favored the distribution in the solution. Figure 5 shows the microscopy images of SBA-15-8QSi and SBA-15 matrices on the stainless steel targets. The matrix suspensions containing SBA-15 and SBA-158QSi, respectively, were prepared by dispersing them in methanol at a concentration of about $1 \mathrm{mg} \mathrm{mL}^{-1}$. As shown in Figure 5, it was observed that the matrix layer derived from SBA-15-8QSi (Figure 5a) was obviously more homogeneous than that from SBA-15 (Figure 5b). This may have resulted in the excellent reproducibility discussed in the Detection Limits and Reproducibility section.

\section{Optimizing Sample Preparation Methods}

To obtain the best performance, we optimized the sample preparation methods using the SBA-15-8QSi material, which were expected to affect the MALDITOF-MS analysis. The effect of solvent on the analysis of sucrose was investigated. Considering the solubility and dispersion of the target analyte and matrix, water and methanol were selected as the solvents. It was found that high intensity was obtained when methanol was used, compared with water (Figure S2). This was probably due to the more homogeneous dispersion of the SBA-15-8QSi matrix in methanol, even though the target analyte, sucrose, was very soluble in both water and methanol. Therefore, the subsequent MALDI-TOF-MS analyses were performed using methanol as the solvent.

There are various types of sample preparation methods for MALDI-TOF-MS analysis, such as the drieddroplet [1], fast evaporation [33], vacuum drying [34], sandwich [35], and two-layer [36] methods. Among these techniques, the dried-droplet method is one of the most frequently used for MALDI-TOF-MS analysis in the case of solution (analyte) to solution (matrix) conditions. In the case of nano-particles, the matrix is a slurry and the analyte is a solution. Therefore, the spot formed by the dried-droplet method might be inhomogeneous, resulting in poor shot-to-shot and sample-tosample reproducibility [37]. To investigate possible improvements in spot homogeneity, four sample preparation methods using the SBA-15-8QSi matrix were compared in the present study. The methods tested were (1) dried-droplet, (2) matrix-first two layer, (3) sample-first two layer, and (4) sandwich. As shown in Figure S3, the sample-first two layer method exhibited the best performance on MALDI-TOF-MS analysis of sucrose. In the case of the sample-first two layer method, the SBA-15-8QSi matrix was deposited as an upper layer on the target analyte, so that the matrix could be dispersed on the entire sample surface, giving a smoother and more homogeneous sample spot. The upper layer of the SBA-15-8QSi matrix can first be irradiated with the laser, which results in an increase in the local temperature and other energies such as kinetic energy [38]. The energies thus generated can be transferred to the bottom layer containing the analyte molecules, allowing desorption and ionization of the molecules.

The ratios between the analyte and matrix are also very important in the analysis using MALDI-TOF-MS. The ratios between SBA-15-8QSi and sucrose were varied from $10: 1$ to $10: 10$ by 0.5 units, and the results indicated that the optimal ratio of SBA-15-8QSi to sucrose was 10:3.5. Under the same analytical conditions, the signal intensity increased until the ratio reached 10:3.5, and then decrease at ratios above this value. In addition, good reproducibility was obtained at this ratio.

\section{Detection Limits and Reproducibility}

To examine the detection limits, a series of L-Arginine$\mathrm{HCl}$ solutions at different concentrations were exam-
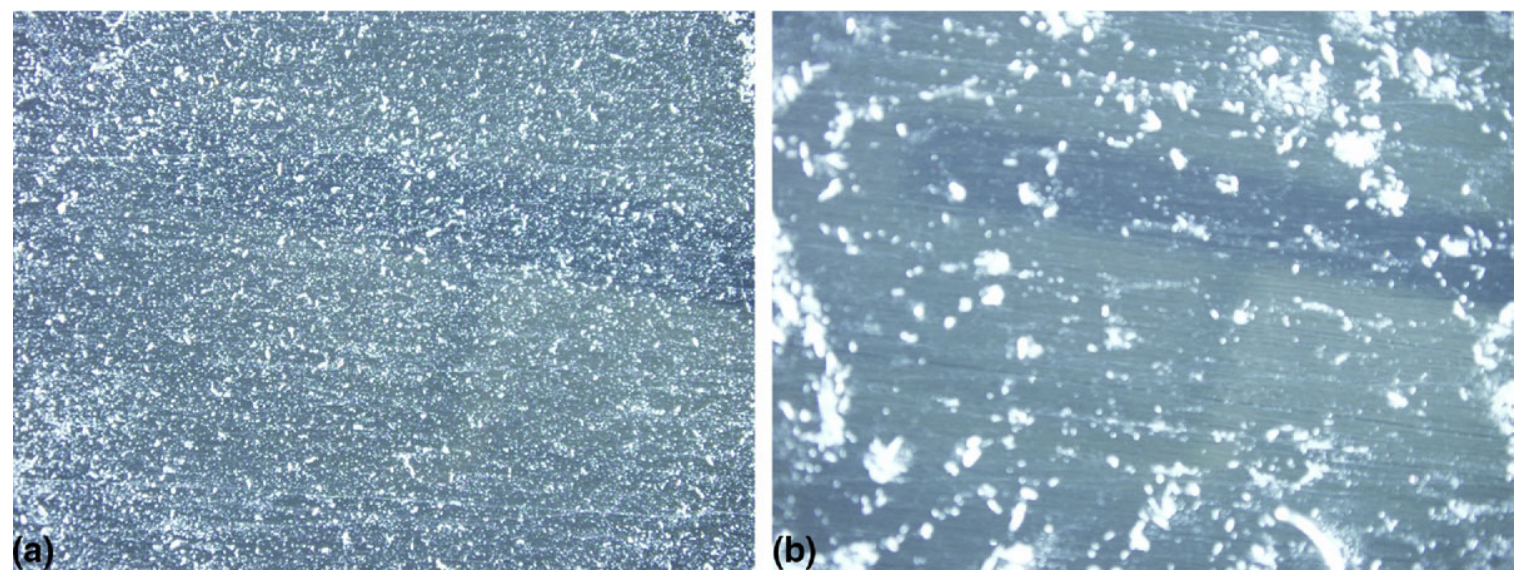

Figure 5. The microscopy images of (a) SBA-15-8QSi and (b) SBA-15 dispersed on the stainless steel target. 
ined using the optimized analytical method discussed previously. According to the results, $8 \mathrm{pmol}$ of LArginine- $\mathrm{HCl}$ was enough to obtain a reasonable MALDITOF-MS spectrum (intensity $=5 \mathrm{~S} / \mathrm{N}$ shown in Figure $6 \mathrm{a}$ inset), indicating that the SBA-15-8QSi matrix exhibited excellent detection limits due to significant suppression of interference ions (shown in Figure 1). To evaluate the reproducibility of analysis, a set of experiments with a sample concentration of $3.5 \mathrm{mg} \mathrm{Ml}{ }^{-1}$ was conducted using 50 different sample spots. The relative standard deviation (RSD) for the signal intensity was below $29 \%$. This RSD value was excellent compared with that of a standard MALDI matrix such as DHB, presumably because the SBA-15-8QSi matrix is much more homogeneous without the "sweet spots" found in traditional chemical matrices.

\section{Applications to Small Molecule Analysis}

The SBA-15-8QSi matrix was applied to the MALDITOF-MS analysis of small molecules because the material exhibited excellent performance as a matrix in the analysis of sucrose and L-Arginine- $\mathrm{HCl}$. A mixture of amino acids, including L-arginine- $\mathrm{HCl}$, L-histidine, Llysine- $\mathrm{HCl}$, L-phenylalanine, metabolites including Lcarnosine, cytidine, and low molecular weight saccharides including xylose, glucose, and sucrose as samples of small molecules were investigated. As shown in Figure $6 \mathrm{a}$, it was obvious that peaks for L-arginine- $\mathrm{HCl}$ $\left(175[\mathrm{M}-\mathrm{HCl}+\mathrm{H}]^{+}\right)$, L-histidine $\left(156[\mathrm{M}+\mathrm{H}]^{+} ; 178\right.$ $\left.[\mathrm{M}+\mathrm{Na}]^{+} ; 194[\mathrm{M}+\mathrm{K}]^{+}\right)$, L-lysine- $\mathrm{HCl}(169[\mathrm{M}-\mathrm{HCl}+$ $\left.\mathrm{Na}^{+}\right)$, L-phenylalanine $\left(188[\mathrm{M}+\mathrm{Na}]^{+} ; 204[\mathrm{M}+\mathrm{K}]^{+}\right)$, L-carnosine $\left(226[\mathrm{M}+\mathrm{H}]^{+} ; 249[\mathrm{M}+\mathrm{Na}]^{+} ; 265[\mathrm{M}+\right.$ $\left.\mathrm{K}]^{+}\right)$, cytidine $\left(266[\mathrm{M}+\mathrm{Na}]^{+} ; 282[\mathrm{M}+\mathrm{K}]^{+}\right)$, xylose
$\left(173[\mathrm{M}+\mathrm{Na}]^{+}\right)$, glucose $\left(203[\mathrm{M}+\mathrm{Na}]^{+} ; 219[\mathrm{M}+\right.$ $\left.\mathrm{K}^{+}\right)$, and sucrose $\left(365[\mathrm{M}+\mathrm{Na}]^{+}\right)$were observed. The results indicate that SBA-15-8QSi matrix approach is suitable for carbohydrates analysis since most of the molecules are observed with $\mathrm{Na}^{+}$and $\mathrm{K}^{+}$adducts. Then, this method was applied for honey analysis to further explore the practical application of SBA-15$8 Q S i$. The honeys were obtained from local bee farms. It is known that the main components of honey are glucose and fructose. Figure $6 b$ and $b$ (inset) were obtained from the standard spiked honey and natural honey, respectively. The peaks of $m / z$ at 365 and 381 represent the $\mathrm{Na}^{+}$and $\mathrm{K}^{+}$adduct ions for sucrose, and the peaks of $m / z$ at 203 and 219 belong to the $\mathrm{Na}^{+}$and $\mathrm{K}^{+}$adduct ions for glucose or fructose. The application studies on distinction of natural product quality with SBA-15-8QSi as matrix were conducting in our laboratory in recent.

\section{Conclusion}

In this work, SBA-15-8QSi was prepared and applied to the analysis of small molecules using MALDI-TOF-MS as the functional matrix. The technique was used to analyze analytes including amino acids, metabolites, and honey. According to the above experiments, no fragments of analyte ions were observed, suggesting that the matrix of SBA-15-8QSi may be a "soft" matrix for MALDI-TOF-MS. Compared with a conventional chemical matrix such as DHB, utilization of the SBA15-8QSi matrix for MALDI-TOF-MS analysis has several advantages, including more homogeneity, better desorption/ionization efficiency for the analytes, and better reproducibility of peak intensities for the analyte
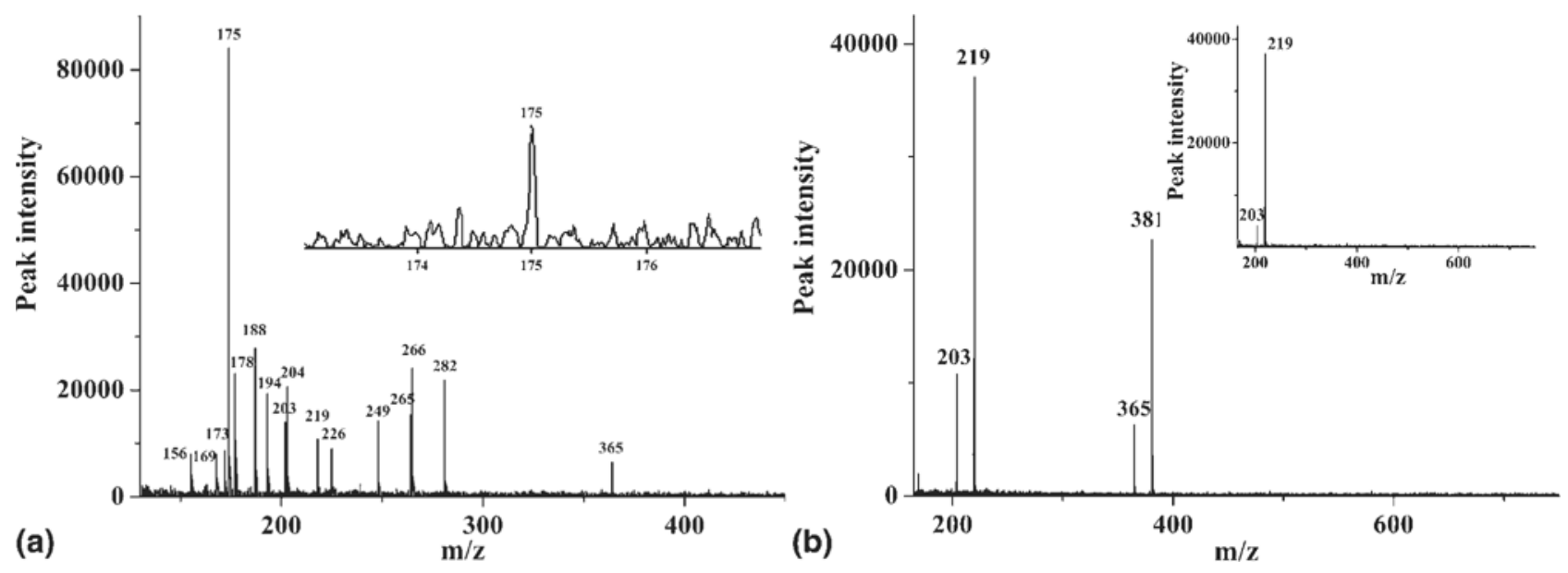

Figure 6. Application of the SBA-15-8QSi matrix in MALDI-TOF-MS analysis of low molecular weight molecules: (a) a mixture of nine small molecules including L-Arginine- $\mathrm{HCl}(175[\mathrm{M}-\mathrm{HCl}+$ $\left.\mathrm{H}]^{+}\right)$, L-Histidine $\left(156[\mathrm{M}+\mathrm{H}]^{+} ; 178[\mathrm{M}+\mathrm{Na}]^{+} ; 194[\mathrm{M}+\mathrm{K}]^{+}\right)$, L-Lysine-HCl $(169[\mathrm{M}-\mathrm{HCl}+$ $\left.\mathrm{Na}]^{+}\right)$, L-Phenylalanine $\left(188[\mathrm{M}+\mathrm{Na}]^{+} ; 204[\mathrm{M}+\mathrm{K}]^{+}\right)$, L-Carnosine $\left(226[\mathrm{M}+\mathrm{H}]^{+} ; 249[\mathrm{M}+\mathrm{Na}]^{+}\right.$; $\left.265[\mathrm{M}+\mathrm{K}]^{+}\right)$, Cytidine $\left(266[\mathrm{M}+\mathrm{Na}]^{+} ; 282[\mathrm{M}+\mathrm{K}]^{+}\right)$, xylose $\left(173[\mathrm{M}+\mathrm{Na}]^{+}\right)$, glucose $(203[\mathrm{M}+$ $\left.\mathrm{Na}]^{+} ; 219[\mathrm{M}+\mathrm{K}]^{+}\right)$, and sucrose $\left(365[\mathrm{M}+\mathrm{Na}]^{+}\right),(\mathbf{b})$ standard spiked honey (glucose or fructose: $203[\mathrm{M}+\mathrm{Na}]^{+} ; 219[\mathrm{M}+\mathrm{K}]^{+}$; sucrose: $365[\mathrm{M}+\mathrm{Na}]^{+} ; 381[\mathrm{M}+\mathrm{K}]^{+}$) and natural honey (glucose or fructose: $\left.203[\mathrm{M}+\mathrm{Na}]^{+} ; 219[\mathrm{M}+\mathrm{K}]^{+}\right)(\mathbf{b}$, inset). The MALDI-TOF mass spectrum of the detection limit is shown (a, inset) for L-Arginine- $\mathrm{HCl}(8 \mathrm{pmol})$. 
sample spots. Under optimized conditions, the detection limit was 8 pmol with the RSD value below $29 \%$. The SBA-15-8QSi matrix can also be utilized practically for examining the purity of natural honey containing low molecular weight saccharides. MALDI-TOF-MS analysis using the present SBA-15-8QSi matrix is believed to be a useful technique to investigate small compounds.

\section{Acknowledgments}

The authors acknowledge support for this study by a grant from the National Natural Science Foundation of China (no. 20767006) and the Ph.D. Programs Foundation of Ministry of Education of China (no. 200801840002). J. M. Kim also thanks to the Korea Science and Engineering Foundation funded by the Ministry of Education, Science and Technology (World Class University Program, R-31-2008-000-10029-0) and the Korea Research Foundation Grants funded by the Korea Government (2009-0076903).

\section{Appendix A Supplementary Material}

Supplementary material associated with this article may be found in the online version at doi:10.1016/ j.jasms.2009.08.003.

\section{References}

1. Karas, M.; Hillenkamp, F. Laser Desorption Ionization of Proteins with Molecular Masses Exceeding 10,000 Daltons. Anal. Chem. 1988, 60, 2299-2301.

2. Tanaka, M.; Waki, H.; Ido, Y.; Akita, S.; Yoshida, T. Protein and Polymer Analyse up to $m / z \quad 10,000$ by Laser Ionization Time-of-Flight Mass Spectrometry. Rapid Commun. Mass Spectrom. 1988, 2, 151-153.

3. Karas, M.; Bahr, U.; Ingendoh, A.; Hillenkamp, F. Laser Desorption/ Ionization Mass Spectrometry of Proteins of Mass 100,000 to 250,000 Dalton. Angew. Chem. Int. Ed. Engl. 1989, 28, 760-761.

4. Chan, T.-W. D.; Colburn, A. W.; Derrick, P. J. Matrix-Assisted Laser Desorption/Ionization Using a Liquid Matrix: Formation of High-Mass Cluster Ions from Proteins. Org. Mass Spectrom. 1992, 27, 53-56.

5. Karas, M.; Bahr, U.; Ingendoh, A.; Nordhoff, E.; Stahl, B.; Strupat, K.; Hillenkamp, F. Principles and Applications of Matrix-Assisted UVLaser Desorption/Ionization Mass Spectrometry. Anal. Chim. Acta 1990, 241, 175-185.

6. Stahl, B.; Steup, M.; Karas, M.; Hillenkamp, F. Analysis of Neutral Oligosaccharides by Matrix-Assisted Laser Desorption Ionization Mass Spectrometry. Anal. Chem. 1991, 63, 1463-1466.

7. Zagorevskii, D. V.; Aldersley, M. F.; Ferris, J. P. MALDI. Analysis of Oligonucleotides Directly from Montmorillonite. J. Am. Soc. Mass Spectrom. 2006, 17, 1265-1270.

8. Bahr, U.; Deppe, A.; Karas, M.; Hillenkamp, F.; Giessmann, U. Mass Spectrometry of Synthetic Polymers by UV-Matrix-Assisted Laser Desorption/Ionization. Anal. Chem. 1992, 64, 2866-2869.

9. Danis., P. O.; Karr, D. E.; Mayer, F.; Holle, A.; Watson, C. H. The Analysis of Water-Soluble Polymers by Matrix-Assisted Laser Desorption Time-of-Flight Mass Spectrometry. Org. Mass Spectrom. 1992, 27, 843-846.

10. McCombie, G.; Knochenmuss, R. Small-Molecule MALDI Using the Matrix Suppression Effect to Reduce or Eliminate Matrix Background Interferences. Anal. Chem. 2004, 76, 4990-4997.

11. LeRiche, T.; Osterodt, J.; Volmer, D. A. An Experimental Comparison of Electrospray Ion-Trap and Matrix-Assisted Laser Desorption/Ionization Post-Source Decay Mass Spectra for the Characterization of Small Drug Molecules. Rapid Commun. Mass Spectrom. 2001, 15, 608-614.

12. Ayorinde, F. O.; Garvin, K.; Saeed, K. Determination of the Fatty Acid Composition of Saponified Vegetable Oils Using Matrix-Assisted Laser Desorption/Ionization Time-of-Flight Mass Spectrometry. Rapid Commun. Mass Spectrom. 2000, 14, 608-615.

13. Ayorinde, F. O.; Hambright, P.; Porter, T. N.; Keith, Q. L. Jr. Use of meso-Tetrakis(Pentafluorophenyl)Porphyrin as a Matrix for Low Molecular Weight Alkylphenol Ethoxylates in Laser Desorption/Ionization
Time-of-Flight Mass Spectrometry. Rapid Commun. Mass Spectrom. 1999, 13, 2474-2479.

14. Guo, Z.; Zhang, Q.; Zou, H.; Guo, B.; Ni, J. A Method for the Analysis of Low-Mass Molecules by MALDI-TOF Mass Spectrometry. Anal. Chem. 2002, 74, 1637-1641.

15. Kinumi, T.; Saisu, T.; Takayama, M.; Niwa, H. Matrix-Assisted Laser Desorption/Ionization Time-of-Flight Mass Spectrometry Using an Inorganic Particle Matrix for Small Molecule Analysis. J. Mass Spectrom. 2000, 35, 417-422.

16. Michalak, L.; Fisher, K. J.; Alderdice, D. S.; Jardine, D. R.; Willett, G. D. C. $60^{-}$Assisted Laser Desorption-Ionization Mass Spectrometry. Org. Mass Spectrom. 1994, 29, 512-515.

17. Shen, Z.; Thomas, J. J.; Averbuj, C.; Broo, K. M.; Engelhard, M.; Crowell, J. E.; Finn, M. G.; Siuzdak, G. Porous Silicon as a Versatile Platform for Laser Desorption/Ionization Mass Spectrometry. Anal. Chem. 2001, 73, 612-619.

18. Lee, C. S.; Lee, J. H.; Kang, K. K.; Song, H. M.; Kim, I. H.; Rhee, H. K.; Kim, B. G. Laser Desorption/Ionization-Mass Spectrometry Using Mesoporous Silicate as Matrix for the Analysis of Various Molecules. Biotechnol. Bioprocesses Eng. 2007, 12, 174-179.

19. Lee, C. S.; Kang, K. K.; Kim, J. H.; Kim, Y. G.; Shim, H. W.; Hwang, T. S.; Rhee, H. K.; Kim, B. G. Analysis of Small Molecules by Desorption/ Ionization on Mesoporous Silicate (DIOM)-Mass Spectrometry (MS) Microporous Mesoporous Mater. 2007, 98, 200-207.

20. Wen, X.; Dagan, S.; Wysocki, V. H. Small-Molecule Analysis with Silicon-Nanoparticle-Assisted Laser Desorption/Ionization Mass Spectrometry. Anal. Chem. 2007, 79, 434-444.

21. Xu, S.; Li, Y.; Zou, H.; Qiu, J.; Guo, Z.; Guo, B. Carbon Nanotubes as Assisted Matrix for Laser Desorption/Ionization Time-of-Flight Mass Spectrometry. Anal. Chem. 2003, 75, 6191-6195.

22. McLean, J. A.; Stumpo, K. A.; Russell, D. H. Size-Selected (2-10 nm) Gold Nanoparticles for Matrix Assisted Laser Desorption Ionization of Peptides. J. Am. Chem. Soc. 2005, 127, 5304-5305.

23. Zhao, D.; Feng, J.; Huo, Q.; Melosh, N.; Fredrickson, G. H.; Chmelka B. F.; Stucky, G. D. Triblock Copolymer Syntheses of Mesoporous Silica with Periodic 50 to 300 Angstrom Pores. Science 1998, 279, 548-552.

24. Zhao, D.; Sun, J.; Li, Q.; Stucky, G. D. Morphological Control of Highly Ordered Mesoporous Silica SBA-15. Chem. Mater. 2000, 12, 275-279.

25. Liu, J.; Shin, Y.; Nie, Z.; Chang, J. H.; Wang, L. Q.; Fryxell, G. E.; Samuels, W. D.; Exarhos, G. J. Molecular Assembly in Ordered Mesoporosity: A New Class of Highly Functional Nanoscale Materials. J. Phys. Chem. A 2000, 104, 8328-8339.

26. Kim, S. W.; Son, S. U.; Lee, S. I.; Hyeon, T.; Chung, Y. K. Cobalt on Mesoporous Silica: The First Heterogeneous Pauson-Khand Catalyst. J. Am. Chem. Soc. 2000, 122, 1550-1551.

27. Han, Y. J.; Kim, J. M.; Stucky, G. D. Preparation of Noble Metal Nanowires Using Hexagonal Mesoporous Silica SBA-15. Chem. Mater. 2000, 12, 2068-2069.

28. Lee, J.; Yoon, S.; Oh, S. M.; Shin, C. H.; Hyeon, T. Development of a New Mesoporous Carbon Using an HMS Aluminosilicate Template**. Adv. Mater. 2000, 12, 359-362.

29. Hu, L.; Zhou, H.; Li, Y.; Sun, S.; Guo, L.; Ye, M.; Tian, X.; Gu, J.; Yang, S.; Zou, H. Profiling of Endogenous Serum Phosphorylated Peptides by Titanium (IV) Immobilized Mesoporous Silica Particles Enrichment and MALDI-TOFMS Detection. Anal. Chem. 2009, 81, 94-104.

30. Li, L. L.; Sun, H.; Fang, C. J.; Xu, J.; Jin, J. Y.; Yan, C. H. Optical Sensors Based on Functionalized Mesoporous Silica SBA-15 for the Detection of Multianalytes $\left(\mathrm{H}^{+}\right.$and $\left.\mathrm{Cu}^{2+}\right)$ in water. J. Mater. Chem. 2007, 17, 4492-4498.

31. Zhao, D.; Huo, Q.; Feng, J.; Chmelka, B. F.; Stucky, G. D. Nonionic Triblock and Star Diblock Copolymer and Oligomeric Surfactant Syntheses of Highly Ordered, Hydrothermally Stable, Mesoporous Silica Structures. J. Am. Chem. Soc. 1998, 120, 6024-6036.

32. Kruk, M.; Jaroniec, M. Characterization of the Porous Structure of SBA-15. Chem. Mater. 2000, 12, 1961-1968.

33. Vorm, O.; Roepstorff, P.; Mann, M. Improved Resolution and Very High Sensitivity in MALDI TOF of Matrix Surfaces Made by Fast Evaporation. Anal. Chem. 1994, 66, 3281-3287.

34. Papac, D. I.; Wong, A.; Jones, A. J. S. Analysis of Acidic Oligosaccharides and Glycopeptides by Matrix-Assisted Laser Desorption/Ionization Timeof-Flight Mass Spectrometry. Anal. Chem. 1996, 68, 3215-3223.

35. Whiteaker, J. R.; Fenselau, C. C.; Fetterolf, D.; Steele, D.; Wilson, D. Quantitative Determination of Heme for Forensic Characterization of Bacillus Spores Using Matrix-Assisted Laser Desorption/Ionization Time-of-Flight Mass Spectrometry. Anal. Chem. 2004, 76, 2836-2841.

36. Dai, Y.; Whittal, R. M.; Li, L. Two-Layer Sample Preparation: A Method for MALDI-MS Analysis of Complex Peptide and Protein Mixtures. Anal. Chem. 1999, 71, 1087-1091.

37. Tholey, A.; Heinzle, E. Ionic (Liquid) Matrices for Matrix-Assisted Laser Desorption/Ionization Mass Spectrometry-Applications and Perspectives. Anal. Bioanal. Chem. 2006, 386, 24-37.

38. Wu, H. P.; Su, C. L.; Chang, H. C.; Tseng, W. L. Sample-First Preparation: A Method for Surface-Assisted Laser Desorption/Ionization Timeof-Flight Mass Spectrometry Analysis of Cyclic Oligosaccharides. Anal. Chem. 2007, 79, 6215-6221. 